\title{
IUGS on conventions and standards in Earth sciences: A matter in need of clarification
}

The International Geological Congress (IGC) was born in 1878 to provide an international forum to the world geological community to consider uniformity in nomenclature and map symbols for geologic reports. The initial steps were taken during the $1^{\text {st }}$ IGC (Paris, 1878), when several commissions were created, i.e. Unification of Geological Nomenclature, Unification of Geological Figures, and Nomenclature of Mineralogical and Paleontological Species. Reports produced by these commissions were discussed during the $2^{\text {nd }}$ IGC (Bologna, 1881), where a "Bureau Géologique International" - the origin of the Commission of the Geological Map of the World (CGMW) - was created to deal with unification of geological methods in the publication of geological maps. Because of the work of the Commission on Unification of Geological Nomenclature, at both the $2^{\text {nd }}$ and $8^{\text {th }}$ IGC (Paris, 1900), a set of stratigraphic terms - and the corresponding chronological terms - was accepted. During the $11^{\text {th }}$ IGC (Stockholm, 1910), the Commission on the Lexicon on Stratigraphy was created, and at the $19^{\text {th }}$ IGC (Algeria, 1952) it was included together with one on Stratigraphic Terminology - later on Stratigraphic Classification (ISSC) - as subcommissions in the new International Commission on Stratigraphy (ICS).

In 1961 the International Union of Geological Sciences (IUGS) was created in order to ensure the progress during the years between Congresses. It was a logical step that the CGMW and the ICS to become associated with IUGS, the former as an affiliated organization and the latter as a commission.

Several ISSC reports presented at the $21^{\text {st }}$ IGC (Copenhagen, 1960), 22 ${ }^{\text {nd }}$ IGC (India, 1964) and $24^{\text {th }}$ IGC (Montreal, 1971) heralded the publication of the International Stratigraphic Guide (ISG) in 1976 which was approved by representatives of many countries and national stratigraphic committees. The ISG was the result of an international consensus on a set of principles embodied in a simple and easily usable classification and terminology. It did not differ substantially from the then in force North American Code of Stratigraphic Nomenclature (NACSN, 1961, AAPG Bulletin, 1961, 45: 645-665), and soon became a model for most National and Regional Stratigraphic Codes. After one hundred years of hard work it seemed that the original goal for the IGC had been achieved, mainly thanks to the efforts of Hollis Hedberg (see ISG, 1994, p. xiv). The ISG was presented as “a recommended approach to stratigraphic classification, terminology and procedure - not as a 'code'", an essential criterion was that "real and lasting progress will be achieved only as geologists in general agree voluntarily on the validity and desirability of certain principles, procedures and terms", and that the ISG "must continually evolve in keeping with the growth of geologic knowledge" (ISG, 1976, p. 4). Thus, the ISG embodied a number of rules, methods, or practices advisable but not required, that were to achieve worldwide consensus.

In 1977, the concept of "depositional sequence" was introduced (Mitchum et al., 1977, AAPG Memoir 26, p. 53), and in 1983 the North American Commission on Stratigraphic Classification (NASCN) published the North American Stratigraphic Code (NASC, 1983, AAPG Bulletin 67:841875; 2005, AAPG Bulletin 89:1547-1591) in which new Stratigraphic categories and terminologies (e.g. lithodemic, allostratigraphic, diachronic, chronometric units) were introduced. Subsequently, a number of other Stratigraphic methodologies began to be applied, such as astronomical calibration of sedimentary cycles. Despite this new work, the second edition of ISG in 1994, as well as most national and regional codes, still maintained the classic litho-, bio- and chrono-stratigraphic categories accepted in 1976, although with the addition of Magnetostratigraphic and UnconformityBounded Units. Dissenting views and new methodologies were soon to create a more complex panorama. The so-called "Lithodemic Units" prompted the use of other systems of classification and terminology's for non-sedimentary rock bodies. Allostratigraphic Units, "depositional sequences" and Unconformity-Bounded Units resulted in several unresolved discussions on their relationships and possible unification. Clearly these and other matters deserve careful consideration to determine if, as stated in the ISG (1994, p. 2), they meet the ISG's recommendation to introduce "changes dictated by the tests of time and usage and (to) incorporate worthy new views and methods".

Even if the ISG constitutes one of the best known examples of IUGS conventions, during the last 30 years, the IUGS has promoted and supported a number of other recommendations. The following bodies are among those which have made proposals that received IUGS support: (1) IUGS Subcommission on the Systematic of Igneous Rocks between 1973 and 2002 published a number a recommendations aimed at achieving a sustainable classification of, and an appropriate nomenclature for igneous rocks. (2) IUGS Subcommission on Systematics of Metamorphic Rocks between 1985 and 2007 produced a complete nomenclature of metamorphic rocks, with a comprehensive glossary of definitions, sources and etymology of over 1200 terms, and a list of mineral abbreviations; (3) IUGS Task Group on Geochemical Baselines, created in 1998 by the IUGS and the International Association of 
GeoChemistry (IAGC), as a successor to several IGCP's going back to 1988, established protocols for sampling, sample preparation, analytical and data management in order to document the concentration and distribution of chemical elements and species in the Earth's near-surface environment, and to encourage and facilitate the population of the Global Geochemical Reference Network (GRN), which covers the Earth's land surface; (4) IUGS Commission on Geological Science for Environmental Planning (COGEOENVIRONMENT), in 1992 began a work - continued between 2002 and 2005 as the IUGS Geoindicators Initiative (GEOIN), - which resulted in a series of indicators to measure magnitudes, frequencies, rates or trends of geological processes and phenomena that occur at or near the Earth's surface and that are significant for assessing environmental change over periods of 100 years or less; (5) Task Group on Isotopes in Geosciences (TGIG), established by IUGS and the International Union of Pure and Applied Chemistry (IUPAC), has in the last years presented recommendations on the half-lives of ${ }^{238} \mathrm{U},{ }^{235} \mathrm{U}$ and ${ }^{234} \mathrm{U}$, and on a single symbol notation for point in time and time duration.

One of the most significant development of the last decades is due to the ICS's work on the International Stratigraphic Chart, which constitutes the framework on which all geological activities are developed. That work has been directed to achieve a worldwide "chronostratigraphic standardization" based on "Global Boundary Stratotype Sections and Points" (GSSP) - the first of which was established in 1972. The final goal has been to precisely define global units (systems, series, and stages) of the International Chronostratigraphic Chart that are the basis for the units (periods, epochs, and ages) of the International Geologic Time Scale - thus setting global standards for the fundamental scale for expressing the history of the Earth. The letter/number symbols used for divisions down to stage/age rank and the colors of the individual units in this chart are established in close collaboration with the CGMW. Thus two commissions originated in the $1^{\text {st }}$ IGC (Paris, 1878), and reporting to the IUGS-IGC Council, are responsible for the most important Standard in the geological sciences. Here it should be remarked that although the International Chronostratigraphic/Time Chart/Scale and its GSSP's are a bottomup grassroots consensual production of groups of experts from many nationalities working in the ICS subcommissions, they are sanctioned by the IUGS to serve as a standard of reference for the dating of rocks everywhere and for relating rocks everywhere to world geologic history (ISG, 1994, p. 136). As such they are mandatory for the international Earth sciences community.
Alberto C. Riccardi 